\title{
Pancreatic undifferentiated rhabdoid carcinoma: KRAS alterations and SMARCB1 expression status define two subtypes
}

\author{
Abbas Agaimy ${ }^{1}$, Florian Haller ${ }^{1}$, Judith Frohnauer ${ }^{1}$, Inga-Marie Schaefer 2,3 , \\ Philipp Ströbel ${ }^{3}$, Arndt Hartmann ${ }^{1}$, Robert Stoehr ${ }^{1}$ and Günter Klöppel ${ }^{4}$ \\ ${ }^{1}$ Institute of Pathology, University Hospital of Erlangen, Erlangen, Germany; ${ }^{2}$ Department of Pathology, \\ Brigham and Women's Hospital, Harvard Medical School, Boston, MA, USA; ${ }^{3}$ Institute of Pathology, \\ University Medical Center, Göttingen, Germany and ${ }^{4}$ Department of Pathology, Technical University of \\ München, München, Germany
}

\begin{abstract}
Pancreatic undifferentiated carcinoma is a heterogeneous group of neoplasms, including pleomorphic giant cell, sarcomatoid, round cell, and rhabdoid carcinomas, the molecular profiles of which have so far been insufficiently characterized. We studied 14 undifferentiated carcinomas with prominent rhabdoid cells, occurring as advanced tumors in seven females and seven males aged 44-96 years (mean: 65 years). Histologically, 10 tumors qualified as pleomorphic giant cell and 4 as monomorphic anaplastic carcinomas. A glandular component, either in the primary or in the metastases, was seen in 5 out of 14 tumors (4 out of 10 pleomorphic giant cell and 1 out of 4 monomorphic anaplastic subtypes, respectively). Osteoclast-like giant cells were absent. Immunohistochemistry revealed coexpression of cytokeratin and vimentin, and loss of membranous $\beta$-catenin and E-cadherin staining in the majority of cases. Nuclear SMARCB1 (INI1) expression was lost in 4 out of 14 cases (28\%), representing all 4 tumors of the monomorphic anaplastic subtype. FISH and mutation testing of KRAS revealed KRAS amplification in 5 out of $13(38 \%)$ and exon 2 mutations in 6 out of 11 $(54 \%)$ successfully analyzed cases. A strong correlation was found between KRAS alterations (mutation and/or copy number changes) and intact SMARCB1 expression (7 out of $8 ; 87 \%)$. On the other hand, loss of SMARCB1 expression correlated with the absence of KRAS alterations ( 3 out of 5 cases; $60 \%$ ). The results suggest that rhabdoid phenotype in pancreatic undifferentiated rhabdoid carcinomas has a heterogeneous genetic background. SMARCB1 loss is restricted to the anaplastic monomorphic subtype and correlates with the absence of KRAS alterations, whereas the pleomorphic giant cell subtype is characterized by KRAS alterations and intact SMARCB1 expression. Recognition and appropriate subtyping of these rare variants might become necessary for future therapeutic strategies.
\end{abstract}

Modern Pathology (2015) 28, 248-260; doi:10.1038/modpathol.2014.100; published online 8 August 2014

Neoplasms with rhabdoid features occur in diverse organs. Their hallmark is 'rhabdoid cells' containing eosinophilic paranuclear cytoplasmic filamentous inclusions of intermediate filaments that displace the nucleus to the cell periphery. ${ }^{1,2}$ Usually, these neoplasms, most of which occur in childhood, are also anaplastic, co-express cytokeratin and vimentin and are highly aggressive. ${ }^{3}$ In the pancreas, neoplasms with rhabdoid features have been reported

Correspondence: Professor A Agaimy, MD, Pathologisches Institut, Universitätsklinikum Erlangen, Krankenhausstrasse 8-10, Erlangen 91054, Germany.

E-mail: abbas.agaimy@uk-erlangen.de

Received 10 April 2014; revised 30 May 2014; accepted 18 June 2014; published online 8 August 2014 under different names (pleomorphic adenocarcinoma, pleomorphic carcinoma, pleomorphic giant cell carcinoma, sarcomatoid carcinoma, anaplastic carcinoma), ${ }^{4-8}$ but have generally been included in the category of undifferentiated carcinomas, that are considered to be variants of ductal adenocarcinoma. ${ }^{9-12}$ The term 'rhabdoid' was first applied to a pancreatic tumor by Nishihara in $1997 .{ }^{13}$ Since then, six other cases using this term have been reported. ${ }^{14-19}$ The fact that only some of the undifferentiated carcinomas exhibit rhabdoid cells, and the notion that many reports describe not only neoplasms with anaplastic giant cell features, but also carcinomas with a sarcomatoid spindle cell appearance are strong arguments that the category of undifferentiated carcinomas of the pancreas 
includes a spectrum of morphologies that are probably of heterogeneous nature.

SMARCB1 is a member of the chromatin remodeling complex SWI/SNF located at chromosome 22q11.2, which probably functions as a tumor-suppressor gene. $^{20}$ Its gene product SMARCB1 (INI-1) is ubiquitously expressed in all normal human tissue types and in all neoplasms with intact SMARCB1 locus. ${ }^{20}$ In several tumor types, rhabdoid cell morphology has been associated with complete loss of nuclear SMARCB1 as a result of deletions/mutations involving the SMARCB1 locus. ${ }^{21,22}$ However, the concept of 'rhabdoid neoplasms' as uniform and specific entities has been challenged by the occurrence of similar cell types in otherwise differentiated neoplasms ('composite rhabdoid tumors'), which only rarely showed chromosome 22q (SMARCB1) alterations. ${ }^{23,24}$ The increasing availability of more sensitive molecular techniques, and improved immunohistochemical identification of SMARCB1 confirmed the existence of SMARCB1deficient 'true rhabdoid' variants of different epithelial neoplasms in the pancreas, ${ }^{17}$ female genital tract, ${ }^{25}$ gastrointestinal tract, ${ }^{26}$ upper aerodigestive tract, ${ }^{27}$ and other rare sites. Currently, the main entities included under the umbrella of 'SMARCB1deficient neoplasms' are pediatric atypical teratoid/ rhabdoid tumors, malignant rhabdoid tumors of the kidney and of extrarenal soft tissue sites, proximaland distal-type epithelioid sarcoma, renal medullary carcinoma, epithelioid malignant peripheral nerve sheath tumors, and subsets of extra-skeletal myxoid chondrosarcoma/myoepithelial neoplasms of soft tissue. ${ }^{28}$

Studying a series of undifferentiated carcinomas of the pancreas that were predominantly ( $>50 \%$ ) composed of rhabdoid cells, we recognized that their morphology was heterogeneous and allowed the separation of two subtypes: the first with a pleomorphic and the second with a monomorphic anaplastic cell pattern. As it has been recently shown that pancreatic undifferentiated carcinomas frequently show KRAS amplifications, ${ }^{29}$ we aimed to investigate how the molecular changes in these neoplasms (ie, KRAS and SMARCB1 alterations) relate to their heterogeneous morphology. We herein report our experience with 14 pancreatic undifferentiated rhabdoid carcinomas, which we analyzed for SMARCB1 expression and KRAS mutations and/or amplifications. In addition, we performed a comprehensive review of the old and recent literature on comparable neoplasms in order to see how the tumors of our series fit into the clinicopathologic spectrum of this group of pancreatic carcinomas.

\section{Materials and methods}

Formalin-fixed and paraffin-embedded tissue blocks from 14 pancreatic tumors were retrieved from our routine surgical pathology files and from the consultation files of two of the authors (GK and AA). Several consultation cases (dating back to 1980) lacked detailed follow-up data. Included were nonendocrine neoplasms predominantly composed ( $>50 \%$ ) of highly atypical tumor cells with eosinophilic filamentous paranuclear cytoplasmic ('rhabdoid') inclusions. Five of the fourteen tumors also showed a glandular component. Tumors containing spindle cells and squamoid cells as a dominant component or osteoclastic giant cells were excluded. Tissue sections were stained with hematoxylin and eosin and periodic acid-Schiff. Immunohistochemistry was performed on freshly cut $3-\mu \mathrm{m}$ paraffin sections using a fully automated slide preparation system 'Benchmark XT System' (Ventana Medical Systems, Tucson, Arizona, USA). All reagents and buffers were retrieved from Ventana Medical Systems. The antibodies used in this study, epitope retrieval conditions, incubation time, secondary antibody information (catalog number, company, and dilution, incubation time) are given in Table 1. Antigen visualization was done using a Ultra View DAB-Kit (Ventana, catalog 05269806001). Positive and negative controls were used throughout. Loss of SMARCB1 expression was recorded, when the tumor nuclei showed 'clean' negative staining as opposed to unequivocal nuclear staining of the adjacent inflammatory, endothelial, stromal, and normal pancreatic cells. If only isolated tumor cells were SMARCB1 negative or showed weak positive staining, SMARCB1 expression was recorded as intact.

\section{Molecular Analysis and Assessment of Microsatellite Status}

Mutational analysis of KRAS exon 2 was performed at the institutional molecular diagnostics laboratory using standardized protocols. In brief, mutation hotspots in exons 2 (codons 12, 13, 19) and 3 (codon 61 ) of the KRAS gene were analyzed using a singlenucleotide primer extension assay (SNaPshot) as described previously. ${ }^{30}$ KRAS amplification was assessed using a dual color probe (ZytoLight ${ }^{\circledR}$ SPEC KRAS/CEN12 Dual color Probe, Zytovision, Bremerhaven, Germany) according to the instructions of the manufacturer. A KRAS/CEP12 ratio of $>2$ was considered as amplification. Other alterations (monosomy, polysomy) were recorded too. The expression of the mismatch repair proteins was assessed in all cases using immunohistochemical staining for MLH1, PMS2, MSH2, and MSH6 (see Table 1 for detailed antibody sources and staining conditions). Unequivocal nuclear staining in $\geq 10 \%$ of tumor cells was considered retained (normal) expression. Normal mucosa, endothelial cells, and background inflammatory cells served as internal controls. In addition, microsatellite instability status was evaluated in two of the cases by PCR on tumor DNA 
Table 1 Sources of antibodies and conditions of immunohistochemical staining

\begin{tabular}{|c|c|c|c|c|c|}
\hline Antibody & Source & Clone & Dilution & Pretreatment cook buffer and conditions & $\begin{array}{l}\text { Incubation time } \\
\text { and temperature }\end{array}$ \\
\hline Pancytokeratin & Beckmann-Coulter & KL-1 & $1: 100$ & Cook buffer CC1, 36 min at $95^{\circ} \mathrm{C}$ & $\mathrm{RT}, 80 \mathrm{~min}$ \\
\hline EMA & DAKO & E29 & $1: 200$ & Cook buffer CC1, 36 min at $95^{\circ} \mathrm{C}$ & $37^{\circ} \mathrm{C} 32 \mathrm{~min}$ \\
\hline Vimentin & DAKO & V9 & $1: 200$ & Cook buffer CC1, $36 \mathrm{~min}$ at $95^{\circ} \mathrm{C}$ & $37^{\circ} \mathrm{C} 20 \mathrm{~min}$ \\
\hline Desmin & DAKO & D33 & $1: 50$ & Cook buffer CC1, $52 \mathrm{~min}$ at $95^{\circ} \mathrm{C}$ & $37^{\circ} \mathrm{C} 32 \mathrm{~min}$ \\
\hline Protein S100 & Zytomed & $4 \mathrm{C} 4.9$ & $1: 3000$ & Cook buffer CC1, $36 \mathrm{~min}$ at $95^{\circ} \mathrm{C}$ & $37^{\circ} \mathrm{C} 32 \mathrm{~min}$ \\
\hline CD34 & Immunotech & QBEND-10 & $1: 500$ & Cook buffer CC1, $52 \mathrm{~min}$ at $95^{\circ} \mathrm{C}$ & $37^{\circ} \mathrm{C} 48 \mathrm{~min}$ \\
\hline CK7 & DCS & OV-TL 12/30 & 1:1000 & Protease 1; $8 \mathrm{~min}$ & $37^{\circ} \mathrm{C} 32 \mathrm{~min}$ \\
\hline CK20 & DAKO & Ks20.8 & $1: 50$ & Protease 1; $8 \mathrm{~min}$ & $37^{\circ} \mathrm{C} 32 \mathrm{~min}$ \\
\hline E-Cadherin & BD Biosciences & Clone 36 & $1: 2000$ & Cook buffer CC1, $36 \mathrm{~min}$ at $95^{\circ} \mathrm{C}$ & $37^{\circ} \mathrm{C} 32 \mathrm{~min}$ \\
\hline$\beta$-Catenin & BD Biosciences & $14 / \beta$-Catenin & $1: 50$ & Cook buffer CC1, $64 \mathrm{~min}$ at $95^{\circ} \mathrm{C}$ & $37^{\circ} \mathrm{C} 32 \mathrm{~min}$ \\
\hline Ki67 & DAKO & MIB-1 & $1: 100$ & Cook buffer CC1, $52 \mathrm{~min}$ at $95^{\circ} \mathrm{C}$ & $37^{\circ} \mathrm{C} 32 \mathrm{~min}$ \\
\hline SMARCB1 & Zytomed & MRQ-27 & $1: 50$ & Cook buffer CC1, $36 \mathrm{~min}$ at $95^{\circ} \mathrm{C}$ & $37^{\circ} \mathrm{C} 60 \mathrm{~min}$ \\
\hline MLH1 & DAKO & ES05 & $1: 50$ & Cook buffer CC1, $64 \mathrm{~min}$ at $95^{\circ} \mathrm{C}$ & $\mathrm{RT}, 100 \mathrm{~min}$ \\
\hline MSH2 & Ventana & G2-19-1129 & Prediluted & Cook buffer CC1, 64 min at $95^{\circ} \mathrm{C}$ & $37^{\circ} \mathrm{C} 60 \mathrm{~min}$ \\
\hline MSH6 & BD Pharmingen & MSH6 & $1: 300$ & Cook buffer CC1, 76 min at $95^{\circ} \mathrm{C}$ & $37^{\circ} \mathrm{C} 32 \mathrm{~min}$ \\
\hline PMS2 & DAKO & EP51 & $1: 40$ & Cook buffer CC1, $64 \mathrm{~min}$ at $95^{\circ} \mathrm{C}$ & RT, 92 min \\
\hline
\end{tabular}

Abbreviation: RT, room temperature.

extracted from formalin-fixed paraffin-embedded tissue samples using the methods described previously. ${ }^{31}$ One case was analyzed by electron microscopy using paraffin-embedded tissue.

\section{Literature Review}

For comparison of clinicopathological, demographic, and prognostic data with those of our tumor series, we performed a review of the MEDLINE literature dating back to 1968 using the keywords 'undifferentiated carcinoma', anaplastic carcinoma,' pleomorphic carcinoma,' 'pleomorphic adenocarcinoma,' 'sarcomatoid carcinoma,' 'giant cell carcinoma,' 'rhabdoid carcinoma,' and 'carcinoma with rhabdoid features'. Included were only those cases whose clinicopathological and demographic data (age, gender, tumor site, size, metastases, treatment and outcome, presence or absence of well-differentiated component, as listed in Table 4) could be traced back to the individual patients and whose tumor histology fits the above-defined criteria. Cases with missing single criteria such as tumor size or site were included as well. Cases with rhabdoid phenotype seen only at metastatic sites were excluded.

\section{Results}

\section{Clinical and Demographic Features}

The main clinicopathological features of the 14 patients are summarized in Table 2. Patients were seven males and seven females aged 44-96 years (mean age: 65; median: 65 years). Tumors were localized in the pancreas head (9), body (1), tail (3), and unspecified part of pancreas (1). Presenting symptoms included nonspecific abdominal symptoms, weight loss, and deteriorating general condition.
One patient presented with leukocytosis (WBC: $37000 / \mathrm{mm}^{3}$; granulocytes $97 \%$ ) and died 2 days after a biopsy was obtained from the tumor. Nine patients underwent radical surgical procedures that varied based on the specific site of the tumor and achieved free surgical resection margins. One extensively necrotic tumor ruptured intraoperatively. Autopsy and biopsy specimens were obtained from three patients and two patients, respectively. Four of twelve patients in whom detailed data were available had positive regional lymph nodes, seven out of ten patients had intra-abdominal and/or liver metastases and one patient had a lung metastasis. Seven patients died of disease within 2 months (four before any therapy and three after surgical resection). One patient (case 2) is currently under palliative chemoradiotherapy 6 months after biopsy.

\section{Pathological Findings}

Grossly, the tumors were described as huge masses measuring 3-11 cm (mean size: 6; median: $6 \mathrm{~cm}$ ), extensively infiltrating into the peripancreatic tissue and often invading adjacent structures, such as stomach, duodenum, and retroperitoneum. Their cut-surfaces were gray-whitish and friable with extensive areas of necrosis and hemorrhage. One tumor was submitted in pieces because of intraoperative rupture. Histological examination revealed two distinctive cytological patterns: pleomorphic giant cell and monomorphic anaplastic subtype. These two subtypes are described separately.

\section{Pleomorphic Giant Cell Subtype}

Ten of the fourteen tumors qualified as pleomorphic giant cell subtype. They showed highly pleomorphic neoplastic giant cells with abundant eosinophilic 
Table 2 Clinicopathological and molecular features of undifferentiated rhabdoid pancreatic carcinomas, own series $(n=14)$

\begin{tabular}{|c|c|c|c|c|c|c|c|c|c|c|c|}
\hline No & Pattern & $\begin{array}{c}\text { Age } \\
\text { (years)/sex }\end{array}$ & Site & $\begin{array}{l}\text { Size } \\
(\mathrm{cm})\end{array}$ & Treatment & MTS & Outcome & $\begin{array}{l}\text { Glandular } \\
\text { component }\end{array}$ & $\begin{array}{l}\text { KRAS mutation } \\
\text { status }\end{array}$ & KRAS FISH & $\begin{array}{l}\text { SMARCB1 } \\
\text { IHC }\end{array}$ \\
\hline 1 & Pleomorphic giant cell & $68 / \mathrm{F}$ & NS & 6 & Surgery & $\begin{array}{l}\text { Lymph nodes } \\
\text { extensive }\end{array}$ & $\begin{array}{l}\text { Abdominal recurrence, } \\
\text { DOD } 2 \text { mo }\end{array}$ & PanIN3 & p.Gly12Val & Normal & Intact \\
\hline 2 & Pleomorphic giant cell & $62 / \mathrm{M}$ & Body & 6.7 & $\begin{array}{l}\text { Biopsy, } \\
\text { palliative CT }\end{array}$ & Liver & Alive, 6 mo & $\begin{array}{l}\text { Focus of WD- } \\
\text { ADCA }\end{array}$ & WT & Normal & Intact \\
\hline 3 & Pleomorphic giant cell & $58 / \mathrm{F}$ & Tail & NS & Biopsy & Liver, peritoneum & DOD, 2 days & $\begin{array}{l}\text { No (only } \\
\text { biopsy) }\end{array}$ & p.Gly12Val & Normal & Intact \\
\hline 4 & Pleomorphic giant cell & $67 / \mathrm{M}$ & Head & 3 & Autopsy & Liver & DOD, initially & ADCA $(<5 \%)$ & p.Gly12Asp & Amplified & Intact \\
\hline 5 & $\begin{array}{l}\text { Pleomorphic giant cell, } \\
\text { myxoid pseudomucinous }\end{array}$ & $71 / \mathrm{M}$ & Head & 6 & Surgery & No & NA & PanIN1 & NR & Normal & Intact \\
\hline 6 & $\begin{array}{l}\text { Pleomorphic giant cell, } \\
\text { melanoma-like }\end{array}$ & $46 / \mathrm{M}$ & Head & 3 & Surgery & Lymph nodes & NA & No & NR & $\begin{array}{l}\text { Polysomy } \\
\text { (trisomy) }\end{array}$ & Intact \\
\hline 7 & $\begin{array}{l}\text { Pleomorphic giant cell, } 5 \% \\
\text { spindle sarcomatous }\end{array}$ & $96 / F$ & Tail & 6 & Autopsy & Liver & DOD, initially & ADCA $<2 \%$ & p.Gly12Asp & Amplified & Intact \\
\hline 8 & Pleomorphic giant cell & $63 / \mathrm{F}$ & Head & 6 & Surgery & Lymph nodes & NA & No & p.Gln61His & Amplified & Intact \\
\hline 9 & $\begin{array}{l}\text { Pleomorphic giant cell, } \\
\text { myxoid stroma }\end{array}$ & $49 / F$ & Head & 11 & Surgery & Lung & NA & No & NR & Amplified & Intact \\
\hline 10 & Pleomorphic giant cell & $81 / \mathrm{F}$ & Head & 10 & Autopsy & Peritoneum, liver & DOD, initially & No & WT & NR & Intact \\
\hline 11 & Monomorphic anaplastic & $76 / \mathrm{M}$ & Head & 5 & Surgery & NS & DOD, $1 \mathrm{mo}$ & No & WT & Normal & $\begin{array}{l}\text { Complete } \\
\text { loss }\end{array}$ \\
\hline 12 & $\begin{array}{l}\text { Monomorphic anaplastic } \\
\text { angiosarcoma-like }\end{array}$ & $44 / F$ & Head & 6 & Surgery & NS & NA & Yes, minimal & p.Gly12Asp & Amplified & $\begin{array}{l}\text { Complete } \\
\text { loss }\end{array}$ \\
\hline 13 & $\begin{array}{l}\text { Monomorphic small cell } \\
\text { pseudopapillary }\end{array}$ & $72 / \mathrm{M}$ & Head & 4 & Surgery & $\begin{array}{l}\text { Lymph nodes, } \\
\text { liver }\end{array}$ & Died post-operative & No & WT & Normal & $\begin{array}{l}\text { Complete } \\
\text { loss }\end{array}$ \\
\hline 14 & $\begin{array}{l}\text { Monomorphic anaplastic, } \\
\text { prominent granulocytes }\end{array}$ & $61 / \mathrm{M}$ & Tail & 5 & Surgery & $\begin{array}{l}\text { Intra-abdominal, } \\
\text { stomach }\end{array}$ & NA & No & WT & Normal & $\begin{array}{l}\text { Complete } \\
\text { loss }\end{array}$ \\
\hline
\end{tabular}

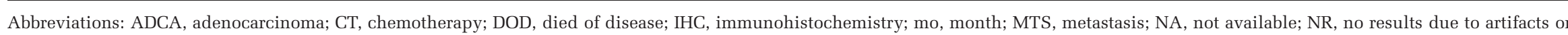
poor preservation; NS, not specified; WD, well differentiated; WT, wild-type. 
cytoplasm frequently containing rhabdoid inclusions (Figure 1a-d). The architectural patterns seen in the two subtypes were similar and varied from a ‘cytology slide'-like poorly cohesive mononuclear cell arrangement to a nested growth or diffuse sheets of compact tumor cells separated by thin fibrovascular septa lacking dense fibrous stroma and showing occasional acantholytic pseudoalveolar spaces. Cytokeratin immunostaining highlighted the striking variation in the size of the tumor cells (Figure 1e). All cases showed intact nuclear SMARCB1 expression (Figure 1f). In addition to strong and consistent cytoplasmic paranuclear expression of vimentin, all cases expressed pancytokeratin but in highly variable pattern (Figure 1e), usually accompanied by variable CK 7 and EMA staining (Table 3). All anaplastic cells of the tumors lost their membranous E-cadherin staining (Figure 2a), but retained it in the glandular components, especially in the lymph node metastasis (Figure 2b). Membranous $\beta$-catenin staining was lost in 10 and focally present in 2 tumors. A variable nuclear staining was seen in a few scattered tumor cells $(<1 \%)$. The proliferation index (MiB1) exceeded $50 \%$ in all cases. Nuclear TP53 labeling was found in four out of seven tumors with assessable staining (Table 3). All other markers (desmin, protein S100, CD34) were not expressed in the tumor cells. The 'rhabdoid' inclusions were found to represent convolutes of intermediate filaments
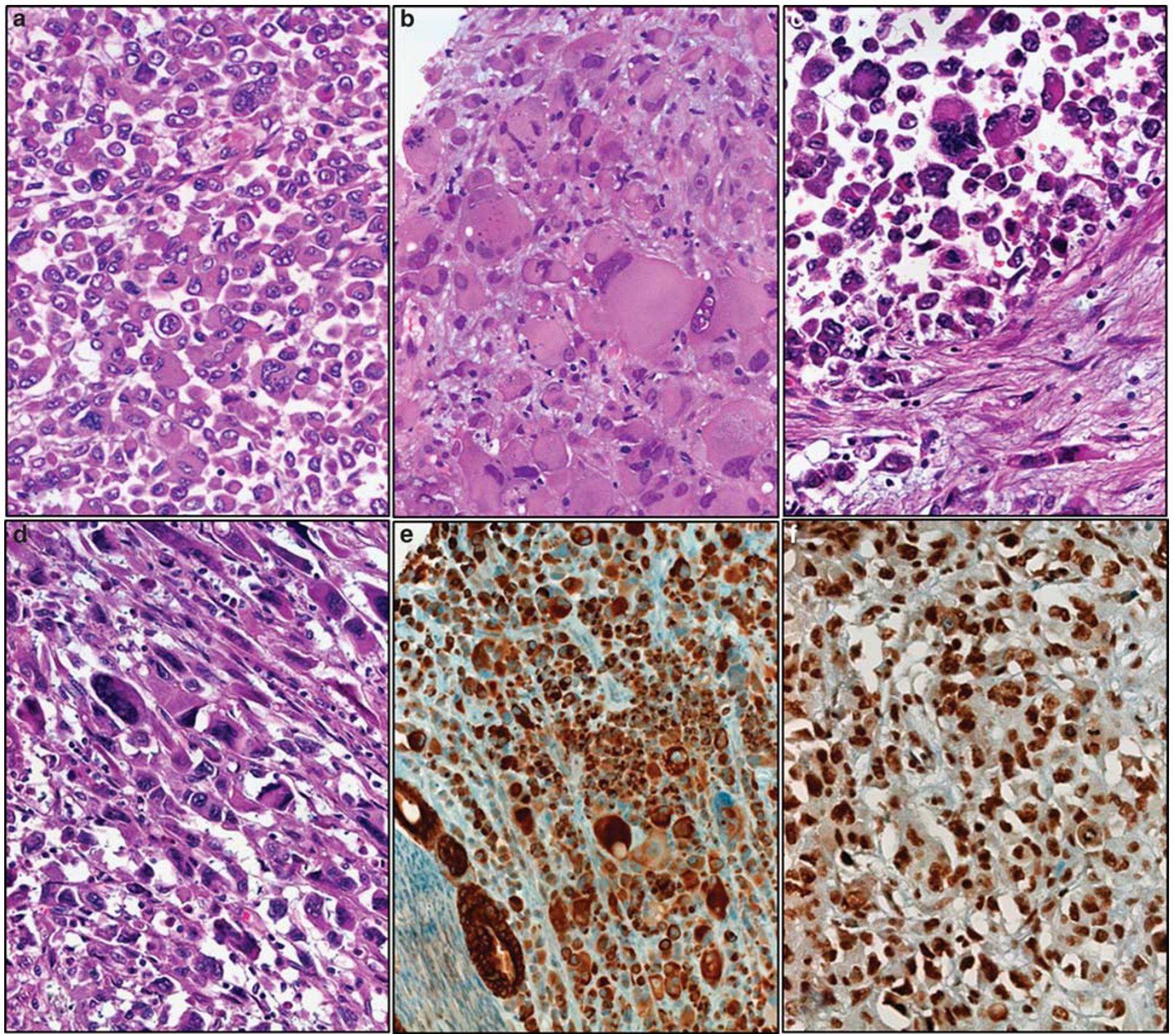

Figure 1 Examples of the pleomorphic giant cell subtype of undifferentiated rhabdoid pancreatic carcinoma. (a) Highly pleomorphic tumor cells with variable nuclear sizes and frequent bi- and multinucleation. Note prominent cytoplasmic eosinophilia with rhabdoid inclusions. (b) Extreme example of cell size variation and eosinophilic cytoplasm. (c) Non-cohesive pseudoalveolar pattern. (d) Sarcomatoid spindle cells. (e) Cell size variation highlighted by pancytokeratin (note perineural carcinomatous glands lower left). (f) Intact nuclear SMARCB1 expression was seen in all cases of this subtype. 
Table 3 Immunohistochemical features of undifferentiated rhabdoid pancreatic carcinomas $(n=14)$

\begin{tabular}{|c|c|c|c|c|c|c|c|c|}
\hline No & Vimentin & $K L-1$ & CK7 & $E M A$ & E-cadherin & $\beta$-Catenin & TP53 & SMARCB1 IHC \\
\hline 1 & +++ & + & - & - & - & - & - & Intact \\
\hline 2 & +++ & +++ & ++ & + & - & - & NR & Intact \\
\hline 3 & +++ & ++ & + & ++ & - & - & NR & Intact \\
\hline 4 & ++ & +++ & +++ & + & - & - & - & Intact \\
\hline 5 & +++ & ++ & + & + & - & - & NR & Intact \\
\hline 6 & +++ & +++ & ++ & ++ & - & + Membranous & - & Intact \\
\hline 7 & ++ & + & + & + & - & - & $40 \%$ & Intact \\
\hline 8 & +++ & +++ & +++ & ++ & - & - & $20 \%$ & Intact \\
\hline 9 & +++ & ++ & - & - & - & + Membranous & $5 \%$ & Intact \\
\hline 10 & - & +++ & ++ & ++ & - & - & $10 \%$ & Intact \\
\hline 11 & +++ & ++ & - & + & - & - & - & Complete loss \\
\hline 12 & +++ & +++ & + & + & - & - & NR & Complete loss \\
\hline 13 & +++ & ++ & - & ++ & - & - & NR & Complete loss \\
\hline 14 & ++ & +++ & - & +++ & - & + + Cytoplasmic + Membranous & $50 \%$ & Complete loss \\
\hline
\end{tabular}

Abbreviations: IHC, immunohistochemistry; NR, no results due to artifacts or poor preservation.
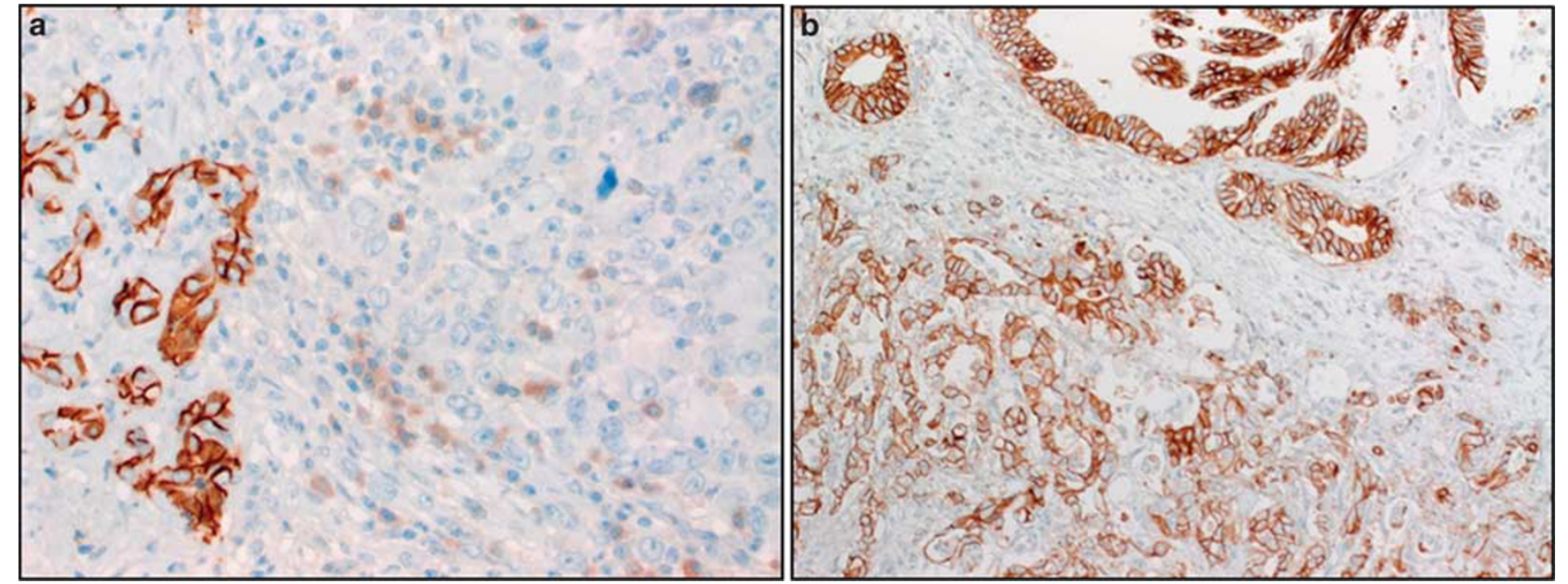

Figure 2 (a) Tumor with complete loss of E-cadherin (in contrast to stained normal glands on the left). (b) Membranous E-cadherin staining of the glandular tumor component in a lymph node metastasis.

on ultrastructural examination of one case (not shown).

\section{Monomorphic Anaplastic Subtype}

Four tumors lacked significant cellular and nuclear pleomorphism and were rather monomorphic, with medium- to large-size vesicular nuclei, prominent nucleoli, and a moderate rim of eosinophilic cytoplasm frequently containing rhabdoid inclusions (Figure 3a). The cells were non-cohesive and loosely arranged without recognizable fibrous stroma. One tumor contained many infiltrating neutrophils (Figure $3 \mathrm{~b}$ ), with occasional cells showing emperipolesis. Another pattern seen in two cases were solid sheets of large epithelioid cells with a variable number of rhabdoid inclusions. This type of growth was frequently associated with prominent vessel-like clefts or hemorrhagic pseudocystic structures closely mimicking epithelioid angiosarcoma (Figure 3c) or proximal-type epithelioid sarcoma (Figure 3d). A mucoid/myxoid stromal pattern was seen focally in one case. Immunohistochemical staining showed similar expression of vimentin and cytokeratin as in the pleomorphic giant cell variant (Figure 3e; Table 3). Nuclear immunostaining for SMARCB1 was completely lost in all four cases (Figure 3f). Other immunohistochemical features were similar to the pleomorphic giant cell subtype. Nuclear TP53 labeling was found in one out of two tumors with evaluable staining (Table 3).

\section{Glandular Differentiation and Other Features}

In the pleomorphic giant cell subtype, foci of neoplastic duct-like glandular structures were seen 

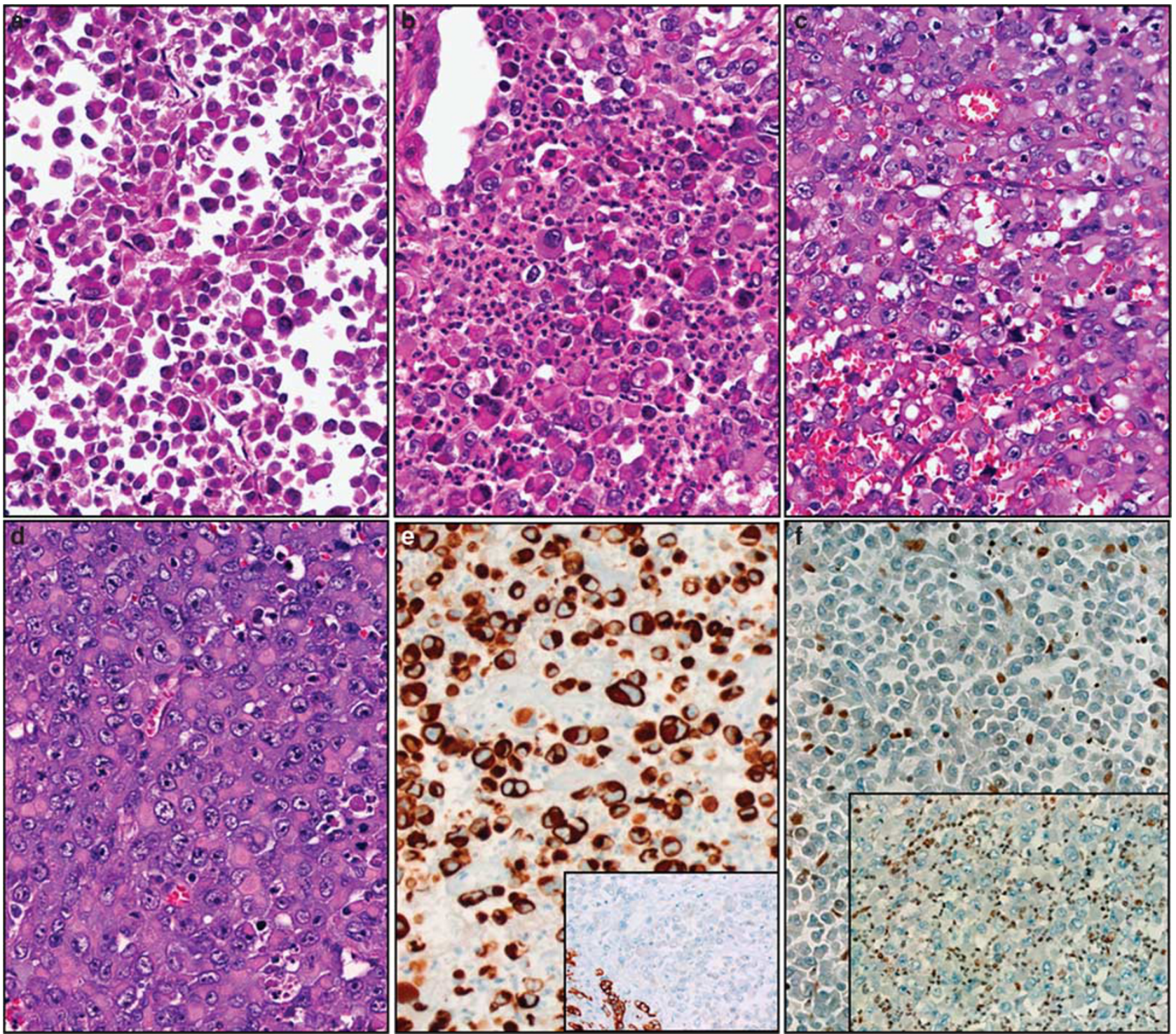

Figure 3 Examples of the SMARCB1-deficient monomorphic subtype. (a) Small to medium sized monotonous rhabdoid cells in pseudoalveolar pattern. (b) Another case showed prominent neutrophilia and focal gland formation (upper left). (c) Epithelioid large cell pattern mimicking angiosarcoma. (d) Compact sheets of large cells with frequent rhabdoid inclusions mimicking proximal-type epithelioid sarcoma. (e) Characteristic paranuclear cytokeratin expression (KL1). Inset: loss of pancytokeratin in another case with focal expression in gland-like areas. (f) Complete loss of nuclear SMARCB1 expression (main image: same case as in a with retained expression in endothelial and stromal cells; inset: same case as in $\mathbf{b}$, with prominent nuclear staining of neutrophils and stromal cells).

in four cases. One case showed only a focus of severely dysplastic pancreatic intraepithelial neoplasia (PanIN 3), but frankly glandular differentiation in a lymph node metastasis (Figure 2b). One tumor showed a focus of perineural glandular differentiation amid highly pleomorphic tumor giant cells (Figure 1e). In the monomorphic subtype, glandular features (seen in only one case) were very subtle and represented either single-scattered glandlike structures or pseudopapillary acantholytic gland-like spaces. The gland-like structures in the monomorphic variant were all SMARCB1 negative similar to the undifferentiated component. Extensive areas of tumor necrosis usually accompanied by severe hemorrhage, prominent lymphovascular invasion, infiltration of arterial vessels, and diffuse lymphoma-like infiltration of peripancreatic fatty tissue were found in all cases.

\section{Molecular Findings}

Molecular analysis revealed KRAS mutations in 6 out of $11(54 \%)$ successfully examined tumors. All mutations were point mutations affecting exon 2 (Table 2). KRAS amplification was detected in 5 out of $13(38 \%)$ cases successfully analyzed by FISH (Figure 4). One additional case showed polysomy 


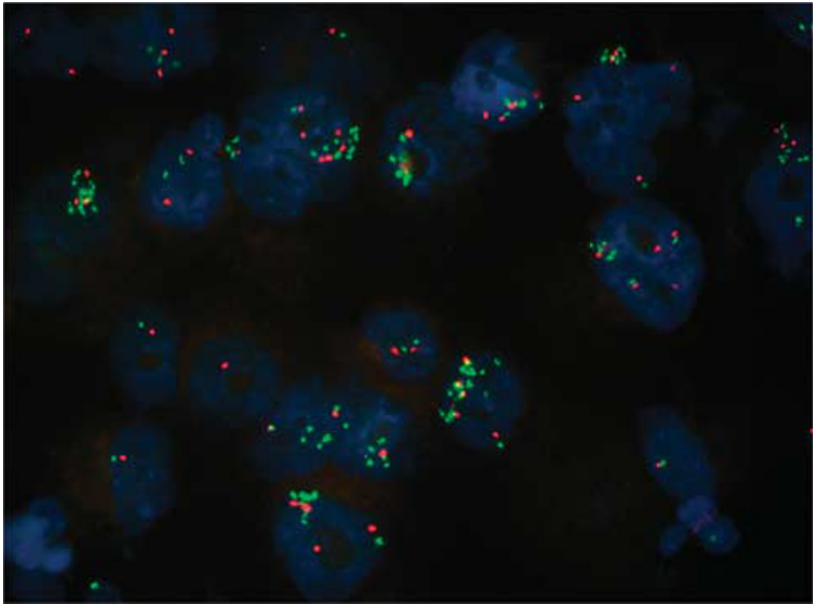

Figure 4 Example of $K R A S$ amplification with $>6$ green signals of KRAS (fluorescence in situ hybridization dual-color probe).

(most cells displayed three signals for $K R A S$ and CEP12). KRAS mutations and KRAS amplification coexisted in four out of six cases $(66 \%)$. On the contrary, all four KRAS wild-type tumors successfully analyzed by FISH lacked KRAS amplification. KRAS amplification correlated with intact SMARCB1 expression in four out of five $(80 \%)$ tumors. Taken together, KRAS alterations (mutations and/or copy number changes) highly correlated with intact SMARCB1 expression (7 out of 8 cases; $87 \%$ ). On the other hand, a strong correlation was found between the absence of KRAS alterations and the loss of SMARCB1 expression (three of five KRAS wild-type cases were SMARCB1 deficient). All but one of the four SMARCB1-negative cases lacked any KRAS alterations.

\section{Literature Review}

Our review of the English literature revealed 46 cases of pancreatic carcinoma that were described in details and fulfill the diagnostic criteria of rhabdoid differentiation as defined in this study. These neoplasms have been reported under different names: pleomorphic adenocarcinoma, pleomorphic carcinoma, pleomorphic giant cell carcinoma, round cell anaplastic carcinoma, sarcomatoid carcinoma, carcinoma with gemistocytes, rhabdoid carcinoma, and carcinoma with rhabdoid phenotype/features. ${ }^{5-8,13-19,32,33}$ Thus, including our cases, a total of 60 rhabdoid carcinomas of the pancreas have been described to date (Tables 2 and 4). Patients were 44 men and 16 women $(\mathrm{M} / \mathrm{F}=2.8: 1)$ aged 30-96 years (mean age: 65 years). In all, $71.6 \%$ of patients were $\geq 60$ years. The tumor originated in the pancreas head (25), body (7), tail (10), diffuse/more than one part (11), and in nonspecified part of pancreas (7).

Most patients presented with locally advanced or widely metastatic disease and received only supportive treatment or palliative surgery with or without chemoradiation. Seventeen patients received surgery as initial and definitive treatment, and three of them also received adjuvant radio/-chemotherapy. Of the remainder, 35 patients underwent biopsy and palliative treatment because of unresectable disease. The tumor was diagnosed at autopsy in five cases. Of four patients who received biopsy followed by radiochemotherapy, three died of disease within 3-13 months and one is alive, currently 6 months under palliative treatment. Lymph node metastases were identified in almost all cases with detailed information ( $>90 \%$ of all). Liver metastases were also seen in the majority of patients, usually shortly after surgical treatment. Follow-up ranging from 1 day to 19 months was available for 49 patients; all but 4 patients $(92 \%)$ died of disease either postoperatively or within 1-19 months (median: 4 months; mean: 5.4 months). All but three patients died within 1 year (Table 2 and Table 4). The four patients who were reported alive had limited follow-up ( $\leq 6$ months) or were recent cases.

In the tumor descriptions, rhabdoid cells dominated the tumor histology in most cases. Occasionally, signet ring-like cells with mucicarmine-positive vacuoles were noted. An adenocarcinoma component of varying degree of differentiation or high-grade intraepithelial neoplasia (PanIN3) were detected in 32 out of $41(78 \%)$ of the cases, in which sufficient tissue was examined. In a few cases, mucinous adenocarcinoma, squamous differentiation, and spindle cell areas were reported. Unequivocal glandular differentiation in metastases in association with a primary tumor, which was devoid of such a component, was noted in four cases. The available immunohistochemical findings consistently demonstrated coexpression of vimentin and pancytokeratin, mostly confined to or highlighting the paranuclear rhabdoid cytoplasmic inclusions.

Molecular data were only available in a single case that showed missense mutation of SMARCB1 in the rhabdoid component. ${ }^{17}$ SMARCB1 expression and KRAS mutation were not tested in the 46 previously reported cases.

\section{Discussion}

According to the current WHO classification of pancreatic tumors, undifferentiated carcinoma is defined as 'a malignant epithelial neoplasm in which a significant component of the neoplasm does not show a definitive line of differentiation. ${ }^{10}$ Included in this definition are histologic variants, such as anaplastic giant cell carcinoma (composed of pleomorphic mononuclear cells admixed with bizarre-appearing eosinophilic giant cells), sarcomatoid spindle cell carcinoma, and carcinosarcoma with recognizable adenocarcinoma and high-grade spindle cell areas, and undifferentiated carcinoma with osteoclast-like giant cells. The 'rhabdoid 
Table 4 Previously reported undifferentiated pancreatic carcinomas with rhabdoid features $(n=46)$

\begin{tabular}{|c|c|c|c|c|c|c|c|c|c|c|c|}
\hline No & Author/reference & Reported as: & $\begin{array}{l}\text { Age (years)/ } \\
\operatorname{sex}\end{array}$ & Site & $\begin{array}{l}\text { Size } \\
(\mathrm{cm})\end{array}$ & Treatment & MTS & Prognosis (mo) & $\begin{array}{l}\text { Glandular } \\
\text { component }\end{array}$ & Vimentin & Cytokeratin \\
\hline 1 & Guillan $^{5}$ & Pleomorphic ADCA & $65 / \mathrm{M}$ & Head & 10 & Palliative & Yes & DOD 3 mo & Present & $\mathrm{ND}$ & ND \\
\hline 2 & Guillan $^{5}$ & Pleomorphic ADCA & $59 / \mathrm{M}$ & Body/tail & 6 & Palliative & Yes & DOD 3 mo & Present & ND & ND \\
\hline 3 & Guillan $^{5}$ & Pleomorphic ADCA & $72 / \mathrm{M}$ & Body/tail & 8 & Palliative & Yes & DOD 4 mo & Present & ND & ND \\
\hline 4 & Guillan $^{5}$ & Pleomorphic ADCA & $75 / \mathrm{M}$ & Body/tail & 9 & Palliative & Yes & DOD 5 mo & Present & ND & ND \\
\hline 5 & Guillan $^{5}$ & Pleomorphic ADCA & $62 / \mathrm{M}$ & Body/tail & 15 & Palliative & Yes & DOD 3 mo & Present & ND & ND \\
\hline 6 & $\begin{array}{l}\text { Alguacil-Garcia } \\
\text { et al }\end{array}$ & Pleomorphic giant cell ca & $78 / \mathrm{M}$ & Body & 30 & Biopsy & Lung, liver & DOD Few days & Present & ND & ND \\
\hline 7 & $\begin{array}{l}\text { Alguacil-Garcia } \\
\text { et } a l^{6}\end{array}$ & Pleomorphic giant cell ca & $74 / \mathrm{M}$ & Tail & 15 & Surgery $+\mathrm{CT}$ & None & DOD $4 \mathrm{mo}$ & Present & ND & ND \\
\hline 8 & 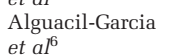 & Round cell anaplastic ca & $51 / \mathrm{F}$ & Head & 5 & Surgery & Lymph nodes & DOD 1 mo & Absent ${ }^{\mathrm{a}}$ & ND & ND \\
\hline 9 & $\begin{array}{l}\text { Alguacil-Garcia } \\
\text { et } a l^{6}\end{array}$ & Round cell anaplastic ca & $73 / \mathrm{M}$ & Diffuse & 11 & Biopsy & Lymph nodes, adrenals & DOD few days & Absent ${ }^{\mathrm{a}}$ & ND & ND \\
\hline 10 & $\begin{array}{l}\text { Alguacil-Garcia } \\
\text { et al }\end{array}$ & Round cell anaplastic ca & $30 / \mathrm{M}$ & Body & 12 & Autopsy & Lymph nodes, ileum, kidney, thyroid, lung & Autopsy & Absent $^{\mathrm{a}}$ & ND & ND \\
\hline 11 & Tschang et $a l^{7}$ & Pleomorphic carcinoma & $67 / \mathrm{M}$ & Tail & 3 & Biopsy & Lymph nodes, liver, extra-abdominal & $\begin{array}{l}\text { DOD median } 3 \text {, mean } \\
6 \mathrm{mo}\end{array}$ & Present & ND & ND \\
\hline 12 & Tschang et $a l^{7}$ & Pleomorphic carcinoma & $49 / \mathrm{M}$ & Tail & NS & Biopsy & Lymph nodes, extra-abdominal & $\begin{array}{l}\text { DOD median } 3 \text {, mean } \\
6 \text { mo }\end{array}$ & Present & ND & ND \\
\hline 13 & Tschang et $a l^{7}$ & Pleomorphic carcinoma & $54 / \mathrm{M}$ & Body + tail & NS & Biopsy & Lymph nodes, liver, extra-abdominal & $\begin{array}{l}\text { DOD median } 3 \text {, mean } \\
6 \text { mo }\end{array}$ & Present & ND & ND \\
\hline 14 & Tschang et al $7^{7}$ & Pleomorphic carcinoma & $65 / \mathrm{M}$ & Tail & NS & Autopsy & Lymph nodes, liver, extra-abdominal & $\begin{array}{l}\text { DOD median 3, mean } \\
6 \text { mo }\end{array}$ & Present & ND & ND \\
\hline 15 & Tschang et al ${ }^{7}$ & Pleomorphic carcinoma & $72 / \mathrm{M}$ & Body & NS & Autopsy & Lymph nodes, liver, extra-abdominal & $\begin{array}{l}\text { DOD median } 3 \text {, mean } \\
6 \mathrm{mo}\end{array}$ & Present & ND & ND \\
\hline 16 & Tschang et al ${ }^{7}$ & Pleomorphic carcinoma & $61 / \mathrm{M}$ & Body & NS & Bioposy & Lymph nodes, liver, peritoneum & $\begin{array}{l}\text { DOD median } 3 \text {, mean } \\
6 \text { mo }\end{array}$ & Present & ND & ND \\
\hline 17 & Tschang et $a l^{7}$ & Pleomorphic carcinoma & $72 / \mathrm{M}$ & Head + body & 10 & Biopsy & Lymph nodes, liver, extra-abdominal & $\begin{array}{l}\text { DOD median } 3 \text {, mean } \\
6 \mathrm{mo}\end{array}$ & Present & ND & ND \\
\hline 18 & Tschang et al $7^{7}$ & Pleomorphic carcinoma & $65 / \mathrm{M}$ & Body + tail & NS & Biopsy + RCT & Lymph nodes, liver, extra-abdominal & $\begin{array}{l}\text { DOD median } 3 \text {, mean } \\
6 \text { mo }\end{array}$ & Present & $\mathrm{ND}$ & ND \\
\hline 19 & Tschang et $a l^{7}$ & Pleomorphic carcinoma & $69 / \mathrm{M}$ & Head & 10 & Biopsy + CT & Liver, peritoneum & $\begin{array}{l}\text { DOD median } 3 \text {, mean } \\
6 \text { mo }\end{array}$ & Present & ND & ND \\
\hline 20 & Tschang et al ${ }^{7}$ & Pleomorphic carcinoma & $65 / \mathrm{M}$ & Body + tail & NS & Biopsy + RCT & Lymph nodes, liver, extra-abdominal & $\begin{array}{l}\text { DOD median } 3 \text {, mean } \\
6 \mathrm{mo}\end{array}$ & Present & ND & ND \\
\hline 21 & Tschang et al ${ }^{7}$ & Pleomorphic carcinoma & $72 / \mathrm{M}$ & Head & 10 & Biopsy & Lymph nodes, liver, extra-abdominal & $\begin{array}{l}\text { DOD median } 3 \text {, mean } \\
6 \text { mo }\end{array}$ & Present & ND & ND \\
\hline 22 & Tschang et $a l^{7}$ & Pleomorphic carcinoma & $53 / \mathrm{M}$ & Diffuse & 10 & Biopsy & Lymph nodes, liver, extra-abdominal & $\begin{array}{l}\text { DOD median } 3 \text {, mean } \\
6 \mathrm{mo}\end{array}$ & Present & ND & ND \\
\hline 23 & Tschang et al & Pleomorphic carcinoma & $81 / \mathrm{F}$ & Body + tail & 15 & Biopsy & Lymph nodes, liver, extra-abdominal & $\begin{array}{l}\text { DOD median } 3 \text {, mean } \\
6 \text { mo }\end{array}$ & Present & ND & ND \\
\hline 24 & Tschang et $a l^{7}$ & Pleomorphic carcinoma & $79 / \mathrm{F}$ & Head & 10 & Biopsy & Lymph nodes & $\begin{array}{l}\text { DOD median } 3 \text {, mean } \\
6 \text { mo }\end{array}$ & Present & ND & ND \\
\hline 25 & Reyes et $a l^{8}$ & Pleomorphic giant cell carcinoma & $59 / \mathrm{M}$ & Head & Mean 9 & Supportive & Lymph nodes, widespread & DOD $1 \mathrm{mo}$ & NA & ND & ND \\
\hline 26 & Reyes et $a l^{8}$ & Pleomorphic giant cell carcinoma & $37 / \mathrm{M}$ & Tail & Mean 9 & RCT & Lymph nodes, widespread & DOD $13 \mathrm{mo}$ & $\mathrm{NA}$ & ND & ND \\
\hline 27 & Reyes et $a l^{8}$ & Pleomorphic giant cell carcinoma & $59 / \mathrm{M}$ & Head & Mean 9 & Supportive & Lymph nodes, widespread & DOD $1 \mathrm{mo}$ & $\mathrm{NA}$ & ND & ND \\
\hline 28 & Reyes et $a l^{8}$ & Pleomorphic giant cell carcinoma & $71 / \mathrm{M}$ & Head & Mean 9 & Palliative surgery & Lymph nodes, widespread & DOD 2 mo & NA & ND & ND \\
\hline 29 & Reyes et $a l^{8}$ & Pleomorphic giant cell carcinoma & $70 / \mathrm{M}$ & Head & Mean 9 & Supportive & Lymph nodes, widespread & DOD 3 mo & $\mathrm{NA}$ & ND & ND \\
\hline 30 & Reves $e t a l^{8}$ & Pleomorphic giant cell carcinoma & $77 / \mathrm{M}$ & Head & Mean 9 & Supportive & Lvmph nodes, widespread & DOD 1 mo & $\mathrm{NA}$ & ND & ND \\
\hline 31 & Reves $e t a l^{8}$ & Pleomorphic giant cell carcinoma & $64 / \mathrm{M}$ & Head & Mean 9 & Supportive & Lvmph nodes, widespread & DOD 2 mo & $\mathrm{NA}$ & ND & ND \\
\hline 32 & Reves $e t a l^{8}$ & Pleomorphic giant cell carcinoma & $62 / \mathrm{M}$ & Head & Mean 9 & Palliative surgery & Lvmph nodes, widespread & DOD 1 mo & $\mathrm{NA}$ & ND & ND \\
\hline 33 & Reyes $e t a l^{8}$ & it cell carcinoma & $54 / \mathrm{M}$ & Body & Mean 9 & Supportive & & DOI & & & ND \\
\hline 34 & Nishihara et al ${ }^{13}$ & Anaplastic ca + rhabdoid features & $52 / \mathrm{F}$ & NS & 10 & Surgery & $\begin{array}{l}\text { Initially lymph nodes, } 9 \text { mo liver MTS }\end{array}$ & & Mucinous & Diffuse & - \\
\hline 35 & Al-Nafussi et a $I^{14}$ & Adenoca + extensive rhabdoid & $77 / \mathrm{F}$ & NS & NS & No & $\begin{array}{l}\text { Soft tissue, liver, lung, kidney, heart, } \\
\text { adrenals }\end{array}$ & DOD initially & PD-ADCA & Diffuse & Diffuse \\
\hline 36 & Kuroda et a $1^{15}$ & $\begin{array}{l}\text { Anaplastic ca with rhabdoid } \\
\text { features }\end{array}$ & $68 / \mathrm{F}$ & NS & 14 & Palliative & $\begin{array}{l}\text { arenals } \\
\text { Regional + bronchial + iliac nodes }\end{array}$ & DOD 2 mo & PD-ADCA & Focal & Diffuse \\
\hline 37 & Chadha et $a 1^{16}$ & $\begin{array}{l}\text { Anaplastic pleomorphic } \\
\text { carcinoma }\end{array}$ & $74 / \mathrm{F}$ & Tail & NS & Palliative & Lymph nodes, liver, adrenal, peritoneum & DOD, $2 \mathrm{wks}$ & Absent in biopsy & NS & Focal \\
\hline 38 & Cho et al ${ }^{17}$ & Mucinous ca + rhabdoid features & $65 / \mathrm{F}$ & Tail & 11 & Surgery $+\mathrm{RT}$ & Omentum + mesentery, liver + lung & DOD $12 \mathrm{mo}$ & Mucinous $2 \mathrm{~cm}$ & Diffuse & Focal \\
\hline 39 & Jamali et $a l^{18}$ & ADSCA + rhabdoid & $75 / \mathrm{M}$ & NS & 3 & Surgery & Liver at $6 \mathrm{mo}$ & DOD 6 mo & ADSCA + PanIN1-3 & Diffuse & Diffuse \\
\hline 40 & Kuroda et a $1^{19}$ & $\begin{array}{l}\text { Anaplastic ca with rhabdoid } \\
\text { features }\end{array}$ & $59 / \mathrm{M}$ & NS & 10 & Surgery + CT & Liver MTS 2 mo & DOD 2 mo & ADSCA $40 \%$ & Focal & Diffuse \\
\hline 41 & Layfield et $a l^{32}$ & Pleomorphic giant cell ca & $71 / \mathrm{M}$ & Head & NS & Surgery & Liver & Alive, $2 \mathrm{mo}$ & NS & NS & NS \\
\hline
\end{tabular}


features' that characterize the pancreatic undifferentiated carcinomas of this series and those described in several other reports ${ }^{5-8,13-19,32,33}$ have not been included into the descriptive terms of the WHO classification. ${ }^{10}$

Here we show that undifferentiated carcinomas of the pancreas exhibiting rhabdoid features vary greatly in morphology, but may be separated into two subtypes, one with a pleomorphic giant cell and another with a monomorphic anaplastic pattern. When these neoplasms were analyzed for KRAS alterations and SMARCB1 expression, a strong correlation was found between histology and molecular findings. KRAS mutations and/or amplification, identified by PCR/sequencing and FISH, respectively, and intact immunohistochemical expression of SMARCB1 (as a highly sensitive and specific marker for intact SMARCB1 locus) were linked to the pleomorphic giant cell subtype, whereas lack of KRAS alterations and loss of nuclear SMARCB1 was found in the majority of monomorphic anaplastic carcinomas.

Recently, KRAS copy number changes or polysomy of chromosome 12 were identified in $42 \%$ of undifferentiated carcinomas of the pancreas but not in ductal adenocarcinomas, and were also found to accompany the intratumoral transition from ductal adenocarcinoma to undifferentiated carcinoma. ${ }^{29}$ In addition, a trend toward more frequent KRAS amplification was observed among cases with mutant allele-specific imbalances. ${ }^{29}$ This study, however, did not focus on tumors with rhabdoid features or the expression of SMARCB1.

Several recent observations support the novel concept of SMARCB1-deficient neoplasms emerging as secondary 'dedifferentiated' clones in the background of a differentiated SMARCB1-positive 'parent' neoplasm (ie, an adenocarcinoma) in different organs including the pancreas. ${ }^{25,26}$ Cho et al ${ }^{17}$ reported on a pancreatic mucinous adenocarcinoma with a 'rhabdoid' component. Molecular analysis revealed a missense SMARCB1 mutation in the rhabdoid component, but SMARCB1 immunostaining was not performed.

Our results confirm and extend the above-mentioned molecular findings in pancreatic undifferentiated carcinomas. First, they demonstrate that KRAS copy number changes on a background of intact SMARCB1 expression are typical for the pleomorphic anaplastic subtype of undifferentiated carcinomas with rhabdoid features. Second, they indicate that SMARCB1-deficient but KRAS-intact undifferentiated rhabdoid carcinomas are characterized by a monomorphic anaplastic histological cell pattern. These findings suggest that the molecular pathway leading to a morphological and biological shift of ductal adenocarcinomas to a highly aggressive pleomorphic anaplastic carcinoma with rhabdoid features is heterogeneous, depending, in case of the pleomorphic subtype, either on mutated and amplified KRAS on a background of intact 
SMARCB1 expression or, in case of the monomorphic subtype, on a loss of SMARCB1 in the presence of wild-type KRAS. The molecular mechanisms that follow these two distinct molecular changes and lead to a switch from a differentiated adenocarcinoma to an undifferentiated carcinoma with rhabdoid appearance and aggressive behavior are not known so far. However, it is likely that the concurrent loss of E-cadherin and $\beta$-catenin from the surface of the tumor cells, noted in this and other studies, ${ }^{34,35}$ is a significant finding contributing to the highly infiltrating growth of the tumors. Concerning the rhabdoid features, which make these tumors so distinct, it can be concluded that their occurrence is not solely caused by loss of SMARCB1 but may also have other causes, as has also been noted in other neoplasms. ${ }^{26,36}$ The exact role of SMARCB1 in the single KRAS mutated case in our series where its loss is likely to be a secondary event in tumorigenesis (as has been shown also in a subset of microsatellite instable colorectal cancer with secondary SMARCB1 loss ${ }^{26}$ ) remains therefore to be determined.

Identification of pancreatic undifferentiated carcinomas with rhabdoid cells in previously published reports is often difficult, because many of these tumors were lumped in the category of pleomorphic giant cell carcinoma or anaplastic carcinoma that also included cases without rhabdoid features. It seems that pancreatic undifferentiated carcinomas with rhabdoid features have first been described under the term pleomorphic carcinoma in 1954 by Sommers and Meissner, who found three such tumors among 142 autopsy cases of pancreatic adenocarcinoma (2\%). ${ }^{4}$ In addition to these cases, we identified 46 other pancreatic tumors with rhabdoid features reported since 1968 (see Table 4). As our review covers a time period of more than 40 years, it is obvious that the relative frequency of these tumors is very low and probably in the range of $1 \%$, particularly, if only surgically treated cases are considered.

The gender distribution and mean age of the patients with pancreatic undifferentiated carcinoma with rhabdoid features as well as the tumor location in the pancreas are similar to the clinicopathological features of pancreatic ductal adenocarcinoma. ${ }^{10-12}$ The prognosis, however, whether the tumor contained a glandular component or not, is worse. ${ }^{5-8}$ According to our review, almost all patients died of their disease or its complication within a mean of 4 months with $>20 \%$ dying immediately or within a few weeks after biopsy or surgery. Tschang et al summarized the 'usual course of events' in these patients with the words 'hospitalization, laparotomy and biopsy, and death.' ${ }^{7}$ This seems to be true until today, irrespective of the treatment modality used. The rapid progress of the tumors may be explained by the complete loss of the adhesion molecules E-cadherin and $\beta$-catenin from the surface of the cells that probably results in a highly aggressive, non-cohesive (lymphoma-like) tumor cell growth, with easy invasion of adjacent organs, vessels, and the retroperitoneum. Adverse systemic effects caused by cytokines produced by the tumor cells seems to be an adverse prognostic factor in some patients. Nakajima et al ${ }^{33}$ reported one patient with rhabdoid carcinoma who presented with a peripheral leucocyte count of $91500 / \mathrm{mm}^{3}$ (neutrophils: $87.5 \%$ ) and elevated serum granulocyte colony-stimulating factor. The patient died 11 days after diagnosis and expression of granulocyte colony-stimulating factor could be demonstrated in tumor cells. Similar to that case, one of our patients presented also with elevated leucocyte count of $37000 / \mathrm{mm}^{3}$ (neutrophils: 97\%) and died 2 days after biopsy. Histologically, prominent granulocytic infiltrates were seen within some tumors.

From a differential diagnostic view point, undifferentiated pancreatic rhabdoid carcinoma needs to be distinguished from proximal-type epithelioid sarcoma of the viscera ${ }^{37,38}$ and from microsatellite instable pancreatic medullary carcinoma with DNA replication errors. ${ }^{39}$ SMARCB1-deficient undifferentiated rhabdoid carcinoma is indistinguishable from rhabdoid cell-dominated epithelioid sarcoma on morphological ground alone. However, identification of a glandular component in $50 \%$ of cases and of a driver KRAS mutation in one of our four cases that are SMARCB1 deficient highlights the epithelial derivation of these neoplasms and argues against a visceral variant of epithelioid sarcoma. Pancreatic medullary carcinoma with DNA replication errors is a rare variant of poorly differentiated non-glandforming carcinoma that is characterized by wildtype KRAS. ${ }^{39}$ In sharp contrast to our series, this subtype shows expanding borders, syncytial growth of tumor cells, lacks rhabdoid cell features, consistently shows loss of mismatch repair proteins and microsatellite instability, and is characterized by prolonged survival. ${ }^{39}$

In summary, our study highlights the phenotypic and molecular heterogeneity of the pleomorphic/ anaplastic variant of pancreatic undifferentiated carcinoma, which has undergone rhabdoid transformation. The clear-cut correlation between tumor histology and molecular findings (KRAS alterations and SMARCB1 expression status) highlights the existence of at least two independent molecular pathways, each associated with its own morphological subtype. The rhabdoid phenotype seems to unify these two subtypes. Although the pathogenesis remains in most parts unclear, KRAS mutation/ amplification on the one side and loss of SMARCB1 on the other side seem to have an essential role for the phenotypic shift from differentiated ductal adenocarcinoma to undifferentiated carcinoma with rhabdoid changes. The results of this study let us therefore assume that the pancreatic undifferentiated carcinomas not only differ in their morphology but also in their molecular profiles. If this assumption is correct, a careful morphological 
separation of the variants using a clear terminology is needed. The nomenclature that has been so far used for these neoplasms is often confusing and may impede appropriate future treatments.

\section{Disclosure/conflict of interest}

The authors declare no conflict of interest.

\section{References}

1 Wick MR, Ritter JH, Dehner LP. Malignant rhabdoid tumors: a clinicopathologic review and conceptual discussion. Semin Diagn Pathol 1995;12:233-248.

2 Fanburg-Smith JC, Hengge M, Hengge UR, et al. Extrarenal rhabdoid tumors of soft tissue: a clinicopathologic and immunohistochemical study of 18 cases. Ann Diagn Pathol 1998;2:351-362.

3 Kerl K, Holsten T, Frühwald MC. Rhabdoid tumors: clinical approaches and molecular targets for innovative therapy. Pediatr Hematol Oncol 2013;30:587-604.

4 Sommers SC, Meissner WA. Unusual carcinomas of the pancreas. Arch Path 1954;58:101-111.

5 Guillan RA. Pleomorphic adenocarcinoma of the pancreas. An analysis of five cases. Cancer 1968;21: 1072-1079.

6 Alguacil-Garcia A, Weiland LH. The histologic spectrum, prognosis, and histogenesis of the sarcomatoid carcinoma of the pancreas. Cancer 1977;39:1181-1189.

7 Tschang TP, Garza-Garza R, Kissane JM. Pleomorphic carcinoma of the pancreas: an analysis of 15 cases. Cancer 1977;39:2114-2126.

8 Reyes CV, Crain S, Wang T. Pleomorphic giant cell carcinoma of the pancreas: a review of nine cases. J Surg Oncol 1980;15:345-348.

9 Hoorens A, Prenzel K, Lemoine NR, et al. Undifferentiated carcinoma of the pancreas: analysis of intermediate filament profile and Ki-ras mutations provides evidence of a ductal origin. J Pathol 1998;185:53-60.

10 Bosman FT, Carneiro F, Hruban RH, Theise ND (eds). World Health Organization Classification of Tumours of the Digestive System. IARC Press: Lyon, 2010.

11 Solcia E, Capella C, Klöppel G. AFIP Atlas of Tumor Pathology: Tumors of the Pancreas, 3rd edn. Series, Fascicle 20. The American Registry of Pathology: Washington, DC, 1997.

12 Hruban RH, Pitman MB, Klimstra DS. AFIP Atlas of Tumor Pathology: Tumors of the Pancreas, 4th Series. Fascicle 6. The American Registry of Pathology: Washington, DC, 2007.

13 Nishihara K, Katsumoto F, Kurokawa Y, et al. Anaplastic carcinoma showing rhabdoid features combined with mucinous cystadenocarcinoma of the pancreas. Arch Pathol Lab Med 1997;121:1104-1107.

14 Al-Nafussi A, O’Donnell M. Poorly differentiated adenocarcinoma with extensive rhabdoid differentiation: clinicopathological features of two cases arising in the gastrointestinal tract. Pathol Int 1999;49:160-163.

15 Kuroda N, Sawada T, Miyazaki E, et al. Anaplastic carcinoma of the pancreas with rhabdoid features. Pathol Int 2000;50:57-62.

16 Chadha MK, LeVea C, Javle M, et al. Anaplastic pancreatic carcinoma. A case report and review of literature. J Pancreas 2004;5:512-515.
17 Cho YM, Choi J, Lee OJ, et al. SMARCB1/INI1 missense mutation in mucinous carcinoma with rhabdoid features. Pathol Int 2006;56:702-706.

18 Jamali M, Serra S, Chetty R. Adenosquamous carcinoma of the pancreas with clear cell and rhabdoid components. A case report. J Pancreas 2007;8:330-334.

19 Kuroda N, Iwamura S, Fujishima N, et al. Anaplastic carcinoma of the pancreas with rhabdoid features and hyaline globule-like structures. Med Mol Morphol 2007;40:168-171.

20 Judkins AR. Immunohistochemistry of INI1 expression: a new tool for old challenges in CNS and soft tissue pathology. Adv Anat Pathol 2007;14:335-339.

21 Biegel JA, Zhou JY, Rorke LB, et al. Germ-line and acquired mutations of INI1 in atypical teratoid and rhabdoid tumors. Cancer Res 1999;59:74-79.

22 Biegel JA, Tan L, Zhang F, et al. Alterations of the hSNF5/INI1 gene in central nervous system atypical teratoid/rhabdoid tumors and renal and extrarenal rhabdoid tumors. Clin Cancer Res 2002;8:3461-3467.

23 Bittesini L, Dei Tos AP, Fletcher CD. Metastatic malignant melanoma showing a rhabdoid phenotype: further evidence of a non-specific histological pattern. Histopathology 1992;20:167-170.

24 Perry A, Fuller CE, Judkins AR, et al. INI1 expression is retained in composite rhabdoid tumors, including rhabdoid meningiomas. Mod Pathol 2005;18:951-958.

25 Donner LR, Wainwright LM, Zhang F, et al. Mutation of the INI1 gene in composite rhabdoid tumor of the endometrium. Hum Pathol 2007;38:935-939.

26 Agaimy A, Rau TT, Hartmann A, et al. SMARCB1 (INI1)-negative rhabdoid carcinomas of the gastrointestinal tract: clinicopathologic and molecular study of a highly aggressive variant with literature review. Am J Surg Pathol 2014;38:910-920.

27 Agaimy A, Koch M, Lell M, et al. SMARCB1/INI1Deficient Sinonasal Basaloid Carcinoma: A Novel Member of the Expanding Family of SMARCB1 Deficient Neoplasms. Am J Surg Pathol; advance online publication, 14 May 2014 (e-pub ahead of print).

28 Hollmann TJ, Hornick JL. INI1-deficient tumors: diagnostic features and molecular genetics. Am J Surg Pathol 2011;35:e47-e63.

29 Krasinskas AM, Moser AJ, Saka B, et al. KRAS mutant allele-specific imbalance is associated with worse prognosis in pancreatic cancer and progression to undifferentiated carcinoma of the pancreas. Mod Pathol 2013;26:1346-1354.

30 Lurkin I, Stoehr R, Hurst CD, et al. Two multiplex assays that simultaneously identify 22 possible mutation sites in the KRAS, BRAF, NRAS and PIK3CA genes. PLoS One 2010;5:e8802.

31 Nardon E, Glavac D, Benhattar J, et al. A multicenter study to validate the reproducibility of MSI testing with a panel of 5 quasimonomorphic mononucleotide repeats. Diagn Mol Pathol 2010;19:236-242.

32 Layfield LJ, Bentz J. Giant-cell containing neoplasms of the pancreas: an aspiration cytology study. Diagn Cytopathol 2008;36:238-244.

33 Nakajima A, Takahashi H, Inamori M, et al. Anaplastic carcinoma of the pancreas producing granulocytecolony stimulating factor: a case report. J Med Case Rep 2008;2:391.

34 Lee HJ, Lee OJ, Jang KT, et al. Combined loss of E-cadherin and aberrant $\boldsymbol{\beta}$-catenin protein expression correlates with a poor prognosis for small intestinal adenocarcinomas. Am J Clin Pathol 2013;139:167-176. 
35 Streit M, Schmidt R, Hilgenfeld RU, et al. Adhesion receptors in malignant transformation and dissemination of gastrointestinal tumors. Recent Results Cancer Res 1996;142:19-50.

36 Pancione M, Remo A, Sabatino L, et al. Rightsided rhabdoid colorectal tumors might be related to the serrated pathway. Diagn Pathol 2013; 8:31.

37 Guillou L, Wadden C, Coindre JM, et al. 'Proximaltype' epithelioid sarcoma, a distinctive aggressive neoplasm showing rhabdoid features. Clinicopatholo- gic, immunohistochemical, and ultrastructural study of a series. Am J Surg Pathol 1997;21:130-146.

38 Sullivan LM, Folpe AL, Pawel BR, et al. Epithelioid sarcoma is associated with a high percentage of SMARCB1 deletions. Mod Pathol 2013;26:385-392.

39 Goggins M, Offerhaus GJ, Hilgers W, et al. Pancreatic adenocarcinomas with DNA replication errors (RER +) are associated with wild-type K-ras and characteristic histopathology. Poor differentiation, a syncytial growth pattern, and pushing borders suggest RER + . Am J Pathol 1998;152:1501-1507. 